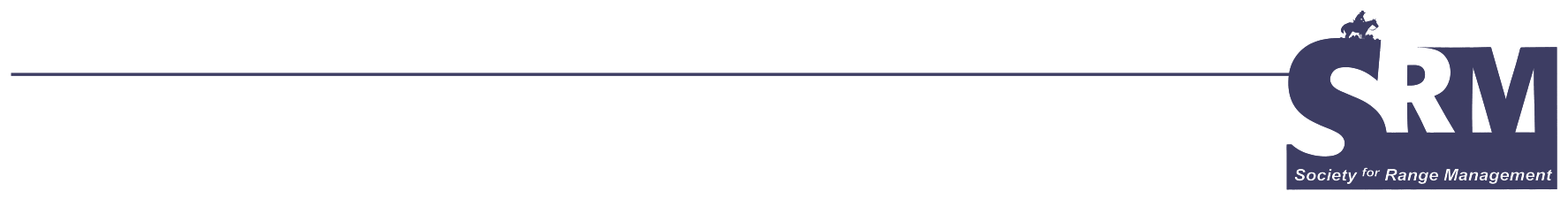

\title{
Cattle and Wooded Draws: A Second Look
}

\section{Vegetation monitoring shows that healthy woodlands and cattle can coexist.}

\section{By Susan E. Boettcher and W. Carter Johnson}

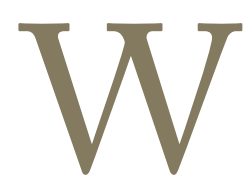

ooded draws or "coulees" in the western Dakotas are associated with the steeper portions of large river valleys such as the Missouri, Cheyenne, and White and their main tributaries. These woodlands are a mixture of green ash, hackberry, American elm, cottonwood, and Rocky Mountain juniper. All but juniper also dominate nearby riparian habitats. Shrub species usually outnumber tree species and are dominated by chokecherry, Saskatoon serviceberry, wild plum, buffalo currant, fragrant sumac, and western snowberry.

The naturally occurring wooded draws of western South Dakota were decimated during homesteading. The combination of heavy woodcutting, severe overgrazing, cultivation of steep land, and the 1930s drought left a deforested, eroded, and ecologically impoverished landscape.

Consolidation of the many failed small farms into large ranches initiated the healing process. For example, a 10,000acre parcel of land farmed by 37 families in 1890 was consolidated into one ranch (the Mortenson Ranch) by the 1950s (Fig. 1). Cultivation ceased except on flat tablelands, grazing intensity was reduced, and trees began to reappear in the draws.

The ranch's riparian forest along the lower Cheyenne River was permanently flooded and destroyed by Oahe Reservoir (Missouri River) in the 1960s. The loss of this forest for overwintering cattle and sheltering of spring calves redirected attention to the restoration of wooded draws as replacement protective habitat. An expansion of trees and

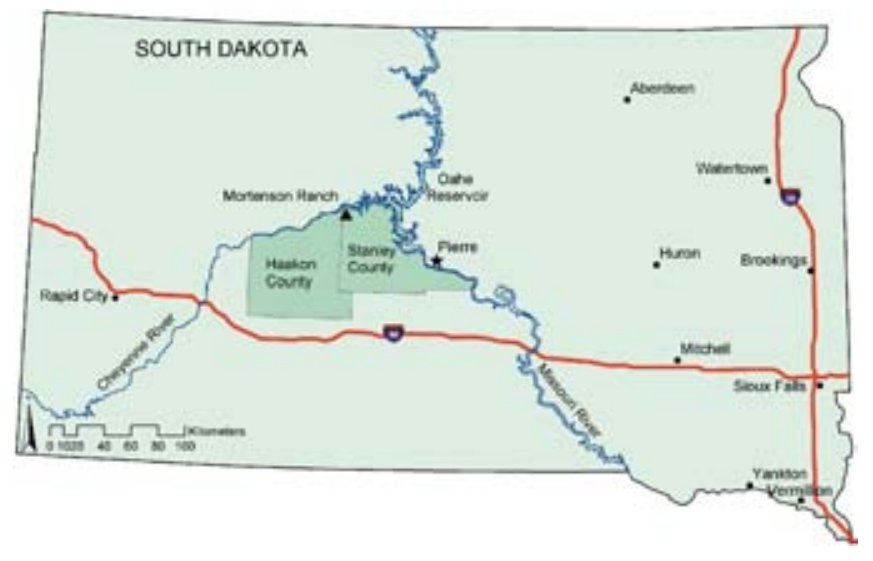

Figure 1. Location of the Mortenson Ranch ( $\mathbf{\Delta})$ in South Dakota.

shrubs followed management changes, which included cross-fencing, adoption of a rest-rotation grazing system, and rapid movement of cattle through about 20 pastures averaging 500 acres each. Riparian areas and wooded draws have been utilized primarily as wintering and calving areas during the nongrowing season.

Permanent photo points and vegetation transects at the Mortenson Ranch were established in the early 1990s and revisited in 2000 to assess the vigor and rate of spread of vegetation in wooded draws. This paper reports those findings. 


\section{Site and Data}

The Mortenson Ranch is located in Stanley County, South Dakota, near the confluence of the Cheyenne and Missouri rivers. The long and deep, east-west running Todd's Draw transects the property.

Vegetation transects and photo points were established in 5 draws (Fig. 2). Four of these were in Todd's Draw, 1 on a southern exposure and 3 on northern exposures, and a 5 th was adjacent to the Cheyenne River floodplain with a western exposure. Three sampling transects were established in each draw. Each was placed perpendicular to the main drainage channel. Transects were extended to or beyond the upslope limit of woody vegetation.

Trees (ie, stems $>2.4$ inches in diameter at breast height [dbh]) and saplings (ie, stems of tree species < 2.4 inches dbh and $>3.3$ feet tall) were sampled on belt transects. Shrub cover (\%) was estimated along the belt transect centerline.
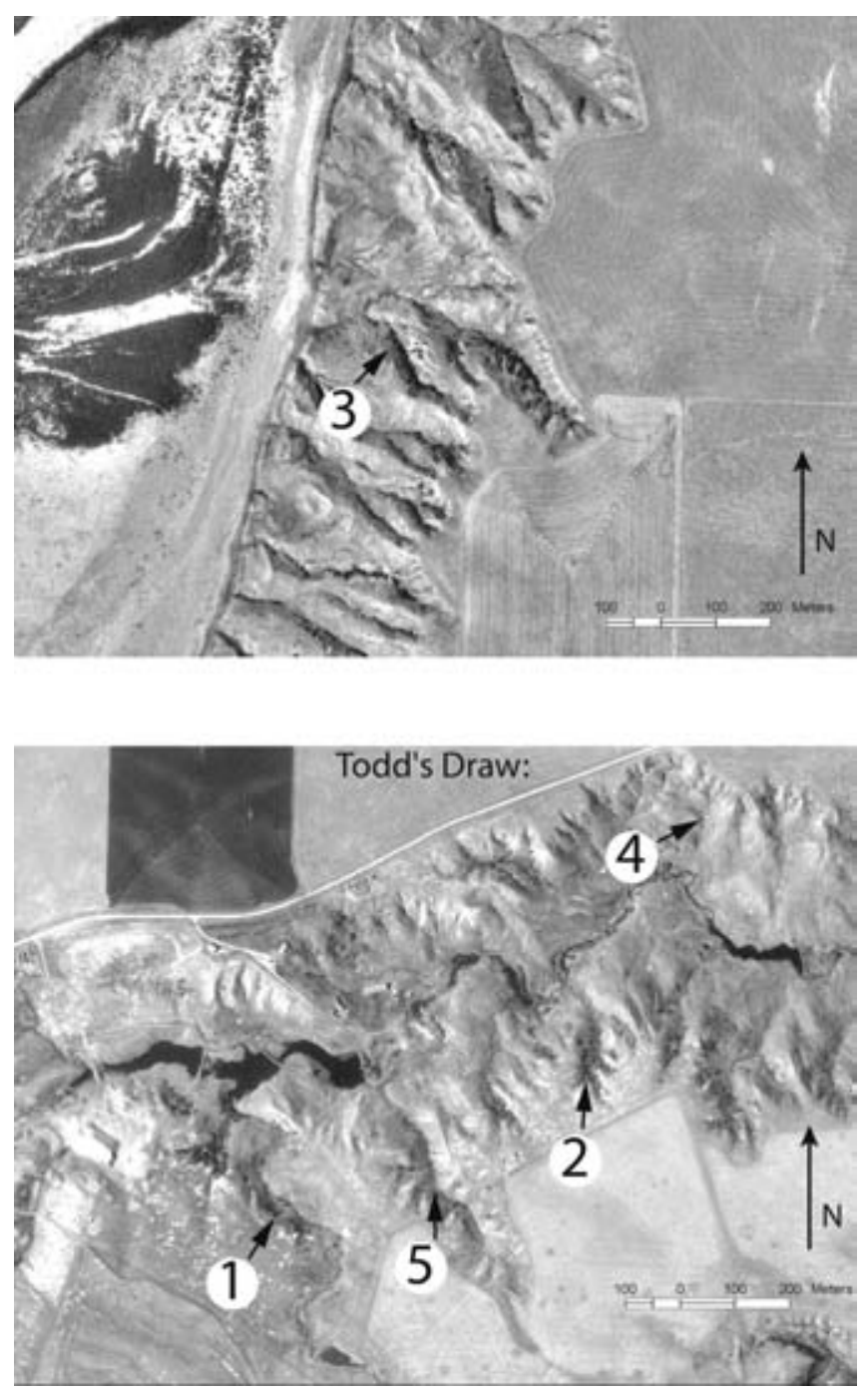

Figure 2. Location of 5 study sites at the Mortenson Ranch in west-central South Dakota.

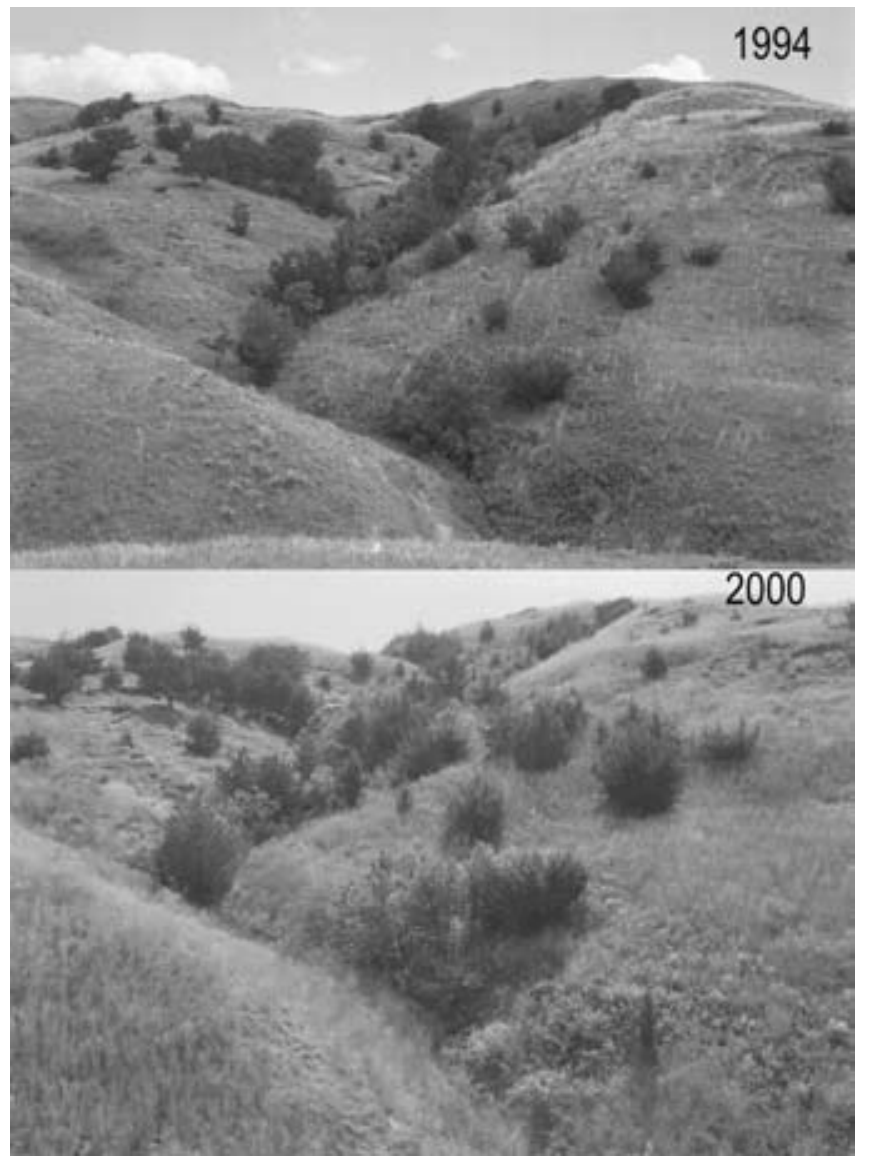

Figure 3. Six years of woody regrowth at site 3 .

Transects were established and trees were sampled in 1992. Saplings and shrubs were first sampled in 1993 and 1994. All sites were resampled in 2000 using the original protocol. Thus, the time interval between measurements ranged from 8 years for trees to $6-7$ years for saplings and shrubs.

\section{Big Changes in a Short Period of Time}

Green ash dominated the draws at both sampling periods, making up about two-thirds of the basal area and three-quarters of the stem density. The other tree species (hackberry, peachleaf willow, cottonwood, Rocky Mountain juniper) were found in only 1 or 2 of the 5 draws, although juniper basal area did exceed that of ash in the west-facing draw.

Although tree composition changed little during the 8year sample interval, the size and number of trees changed dramatically. Increases in basal area and in density were posted at all sites. The average increase in basal area across sites was a remarkable $82 \%$, while the average density of trees increased more modestly, by $40 \%$ (Table 1).

Other woody species increased as well. Sapling numbers, dominated by green ash, increased by $56 \%$, and shrub cover, contributed by 14 species, increased by nearly $40 \%$ (Table 1 ). Eighty percent of the shrub density was contributed by 4 species: wild plum, fragrant sumac, western snowberry, and 
Table 1. Average changes in wooded draws at the Mortenson Ranch

\begin{tabular}{|l|c|c|c|}
\hline Measure & $\begin{array}{c}\text { Early } \\
\mathbf{1 9 9 0 5}\end{array}$ & $\mathbf{2 0 0 0}$ & $\begin{array}{c}\% \\
\text { change }\end{array}$ \\
\hline $\begin{array}{l}\text { Tree basal area } \\
\text { (foot/acre) }\end{array}$ & 17 & 31 & +82 \\
\hline $\begin{array}{l}\text { Tree density } \\
\text { (no./acre) }\end{array}$ & 130 & 182 & +40 \\
\hline $\begin{array}{l}\text { Sapling density } \\
\text { (no./acre) }\end{array}$ & 326 & 510 & +56 \\
\hline \begin{tabular}{l} 
Shrub cover (\%) \\
\hline $\begin{array}{l}\text { Span of woodland } \\
\text { (feet) }\end{array}$
\end{tabular} & 42 & 59 & +40 \\
\hline
\end{tabular}

chokecherry. Woodland expanded upslope along nearly all transects by an average of $16 \%$. Woodland herbs also occur in wooded draws, but these were not sampled.

\section{Impact}

Recovery of wooded draws at the Mortenson Ranch occurred in 2 phases: 1st with land consolidation and halting of most woodcutting and farming beginning in the 1930s, followed by cessation of season-long summer grazing in wooded draws beginning in the 1970s. The new remeasurement data show that trees and shrubs are growing rapidly and more densely, and are expanding their coverage in draws (Fig. 3).

The current vegetation of these draws is similar to that described by explorers and surveyors in the 1800s before significant cutting and cultivation began. All woody species present in samples are native to South Dakota.

Use of these woodlands to overwinter cattle and for spring calving has not curtailed their growth and expansion.
Slower expansion should be expected in the future as woody plants migrating upslope meet increasing moisture limitations. Droughts, such as the one currently in progress in western South Dakota, may thin out woody cover. Future remeasurement of the permanent transects at the Mortenson Ranch can identify when wooded draws have fully recovered from settlement and can detect expansion or retreat in woodland extent caused by weather extremes.

Authors are Research Associate and Professor of Ecology, South Dakota State University, Brookings, SD 57007. Funding was provided by the South Dakota Agricultural Experiment Station (Project SD00048-MS) at South Dakota State University.

\section{Acknowledgments}

We thank Clarence, Curt, Jeff, and Todd Mortenson for making their ranch available for study and encouraging the research and monitoring.

\section{Additional Reading}

Boettcher, S. E., And W. C. Johnson. 1997. Restoring the presettlement landscape in Stanley County, South Dakota. Great Plains Research 7:27-40.

Boettcher, S. E., W. C. Johnson, And F. R. Gartner. 1995. A case study in woodland restoration. Rangelands 17:15-18.

Bradbury, J. 1966. Travels in the interior of America. Ann Arbor, MI: University Microfilms.

Butler, J., AND H. Goetz. 1984. Influence of livestock on the composition and structure of green ash communities in the northern Great Plains. In: D. L. Noble and R. P. Winokur [eds.]. Proceedings of the Symposium on Wooded Draws: Characteristics and Values for the Northern Great Plains. Great Plains Agricultural Council Publication No. 111. p. 44-49.

Rumble, M. M., C. H. Sieg, D. W. Uresk, and J. Javersak. 1998. Native woodlands and birds of South Dakota: past and present. USDA Forest Service Rocky Mountain Research Station Research Paper RMRS-RP-8. 11 p.

WELLS, P. V. 1965. Scarp woodlands, transported grassland soils, and concept of grassland climate in the Great Plains Region. Science 148:246-249. 